\title{
Terrestrial laser scanning in monitoring of anthropogenic objects
}

\author{
Janina Zaczek-Peplinska*, Maria Kowalska \\ Warsaw University of Technology \\ Faculty of Geodesy and Cartography \\ Chair of Geodesy Engineering and Control-Measuring Systems \\ pl. Politechniki 1, 00-661 Warsaw, Poland \\ e-mails: jzaczek@gik.pw.edu.pl; m.kowalska@gik.pw.edu.pl
}

Janina Zaczek-Peplinska http://orcid.org/0000-0003-4875-4250

* Corresponding author: Janina Zaczek-Peplinska

Received: 11 June 2017 / Accepted: 14 August 2017

\begin{abstract}
The registered xyz coordinates in the form of a point cloud captured by terrestrial laser scanner and the intensity values (I) assigned to them make it possible to perform geometric and spectral analyses. Comparison of point clouds registered in different time periods requires conversion of the data to a common coordinate system and proper data selection is necessary. Factors like point distribution dependant on the distance between the scanner and the surveyed surface, angle of incidence, tasked scan's density and intensity value have to be taken into consideration. A prerequisite for running a correct analysis of the obtained point clouds registered during periodic measurements using a laser scanner is the ability to determine the quality and accuracy of the analysed data. The article presents a concept of spectral data adjustment based on geometric analysis of a surface as well as examples of geometric analyses integrating geometric and physical data in one cloud of points: cloud point coordinates, recorded intensity values, and thermal images of an object. The experiments described here show multiple possibilities of usage of terrestrial laser scanning data and display the necessity of using multi-aspect and multi-source analyses in anthropogenic object monitoring. The article presents examples of multisource data analyses with regard to Intensity value correction due to the beam's incidence angle. The measurements were performed using a Leica Nova MS50 scanning total station, Z+F Imager 5010 scanner and the integrated Z+F T-Cam thermal camera.
\end{abstract}

Keywords: terrestrial laser scanning, assessment of the objects, engineering geodesy, Intensity value correction, thermal imaging

\section{Introduction}

Laser scanning has become one of the main tools in mass movement research (Jaboyedoff et al., 2012). The short time of acquisition of source data in the field, very high precision of measurement, multidimensional nature of the acquired source 
data and other characteristics of this method have caused a dynamic progress in usage of laser scanning tools in natural sciences. Data from laser scanning is used in goemorphology (e.g. Jaboyedoff et al., 2012; Owerko et al., 2013), hydrology (e.g. Milan, 2009), forestry (e.g. Alberti et al., 2013), archaeology (Valzano et al., 2005), (Cruthley, 2009), hydraulic engineering and geodetic engineering (Zaczek-Peplinska et al., 2014), glaciology (Pętlicki and Kinnard, 2016) and many other fields. Laser scanning technology can be distinguished into Terrestrial Laser Scanning (TLS) and Airborne Laser Scanning (ALS). The appropriate technique is chosen depending on the type of reports and research, however each of them has its use in surface research, landslide research and engineering object measurements. Due to the different natures of data in TLS and ALS this article concentrates on using data from terrestrial laser scanning.

Xyz coordinates registered as a point cloud and their assigned reflection intensity values (I) allow for geometric as well as spectral analysis. Geometric comparison of point clouds registered at different times in a multi-aspect task, requires unification of data to one coordinate system, as well as appropriate data selection. It is necessary to take into account such factors as point distribution in relation to distance to scanner, the angle of the beam, scan density, and reflection intensity. One of the requirements of appropriate analysis of the periodic measurements of point clouds acquired by the terrestrial laser scanner is the appropriate assessment of quality and precision of analysed data. High reliability results of performed comparisons require:

(a) uniformity in precision of measurement on the entire analysed surface,

(b) uniformity (or as close to uniform as possible) of distribution of registered points on the analysed surface,

(c) adjustment (standardization) of registered intensity values in reference to distance between the surface and the scanning instrument as well as the angle of incidence of the laser beam, in order to make the registered numbers comparable on the entire analysed surface regardless of local laser beam angle of incidence.

Due to the complexity of the aforementioned factors, and the character of the performed measurements, as well as the characteristics of the scanning instrument - increasing distance from scanner to object, up to the borders of scanned area, diminishing density of points and differences in intensity due to the changing angle of incidence, acquisition of a repeatable uniform point cloud is impossible.

Terrestrial laser scanners are also combined with external sensors, so that, apart from geometric data and intensity values it can be obtained a thermal or color information as RBG values. Applications of a thermal camera integrated with a terrestrial laser scanner can be found in construction industry as a mean to detect and evaluate thermal leakage of a building. Thermographic analyses are an important tool in the aspect of integrated energy saving policy. Creation of thermograms of building's external walls and their analysis allow for a non-invasive identification of insulation layer defects and detection of contractor's errors (Malinowski and Sikora, 2013). Thermal images used so far only provided information on the differences in temperature occurring on the surface of the object. In order to carry out a metric evaluation of the estimated 
wastage area additional inventory measurements were necessary (Rutkowska at all, 2013). A terrestrial laser scanner with an integrated thermal camera can, as a part of surface measurement, provide one with a temperature-coloured point cloud, which will make it possible to carry out precise geometric measurements. The data acquired in such fashion may complement existing thermograms and temperature profiles. Through relevant point cloud processing one can obtain metric thermal model of the object.

This article shows an example of an analysis of deformation of a fragment of a point cloud and the attempts at correcting the values of intensity in regards to the laser beam angle of incidence. The second part of the article describes the possibilities of using multi-source data analysis captured from different sensors integrated into one cloud of TLS points.

\section{Methods}

As mentioned in the introduction, the terrestrial laser scanner registers an intensity value for each measured point. That value is the measurement of electric power of the signal received due to transformation and enhancement of the optical power of backscattering. The intensity information is usually used to visually support the representation of point clouds. It does, however, have the potential for a more sophisticated use such as registration and classification of surfaces based on material features recognition (Pfeifer et al., 2007), (Kasalaainen et al., 2011), (Hancock et al., 2012), (Zaczek-Peplinska et al., 2015b).

Measurements made with laser scanners equipped with a measuring tool in the form of a light beam, are based on the signal reflected off of the surface of an object in the direction of the registering unit. The outcome quality depends not only on the measuring tools of the laser scanner itself, but also the reflective properties of different materials. Because of this, beam intensity is becoming more commonly used for classification and adjustment purposes (Voegtle and Wakaluk, 2009). Furthermore, factors such as angle, distance, atmospheric factors, roughness, and level of object humidity can influence registered intensity values. In general, one could state that with the increase of the angle of the beam, the magnitude of the reflection towards the receiver decreases.

Many examples of research and analysis of the influence of the angle of the laser beam on the registered intensity values can be found in the already existing literature. One of the elementary studies on this subject is the measurement experiment described in (Soudarissanane et al., 2007). The results confirmed the predictions of the authors. The intensity values were symmetrical to the $0^{\circ}$ direction. The registered intensity decreased with the increase of the angle of incidence. For angles of incidence close to perpendicular a slight drop of intensity was shown, while the standard deviation rose. Such effects are caused by the saturation of the receiver which happens when the angle of incidence is perpendicular. Research described in (Voegtle and Wakaluk, 
2009), citing from (Kaasalainen et al., 2011) and (Lichti and Gordon, 2004), allow us to draw similar conclusions as in the example of (Soudarissanane et al., 2007). The angle of incidence has a visible influence on the registered intensity values (Figures 1 and 2). The highest value is noted for angles almost perpendicular to the surveyed surface. The authors point out that intensity values increase with the increase of angle of incidence up to $20^{\circ}$ and further note the expected coherence with the cosine law of reflection. It is easy to notice that the differences in distance from the target do not translate directly to registered intensity values.
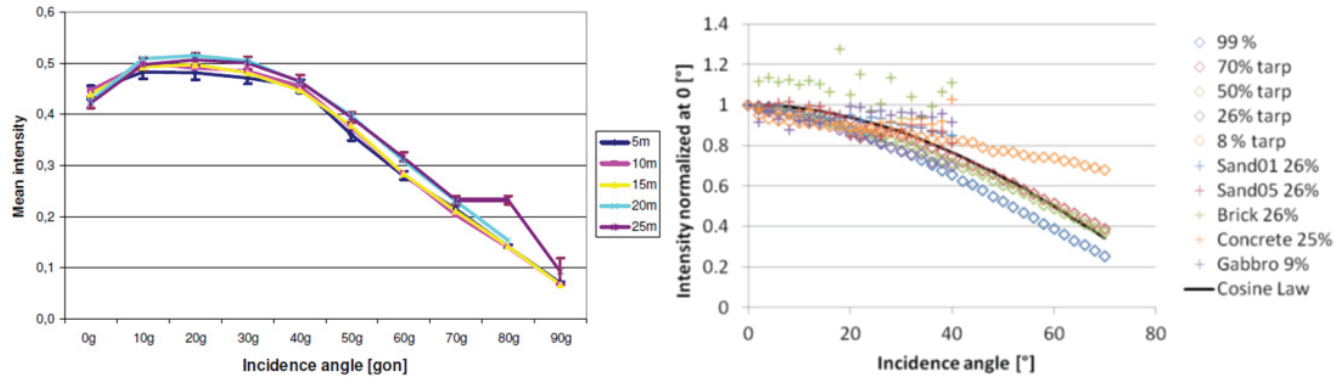

Fig. 1. On left, graph of the average intensity value depending on the angle of incidence

(50\% reflectivity) (Voegtle and Wakaluk, 2009)

On right. The effect of incidence angle on the intensity measured with the FARO scanner. To compare the different targets and the Lambertian (cosine) scattering law, all results have been normalized to $\mathrm{I}\left(0^{\circ}\right)=1$ (Kaasalainen et al., 2011)

On account of these aforementioned phenomena, the authors of this report propose the use of cosine correction in data processing, based on the difference of the angle of incidence of the laser beam on the measured surface (Figure 1). The corrected value of $\mathrm{I}_{\mathrm{H}}$ conforms to the normalized value, observed for a perpendicular angle of incidence on a vertical surface.

$$
I_{H}=I_{S} \frac{\cos \theta_{S}}{\cos i}
$$

where:

$I_{H}-$ intensity observed for vertical surface,

$\mathrm{I}_{\mathrm{S}}$ - intensity observed for sloped surface,

$\mathrm{i}$ - incidence angle in relation to the normal on a point/pixel,

$\theta_{\mathrm{s}}-$ instrument zenith angle.

Relations between examined angles of incidence of the beam shown in Figure 4. 


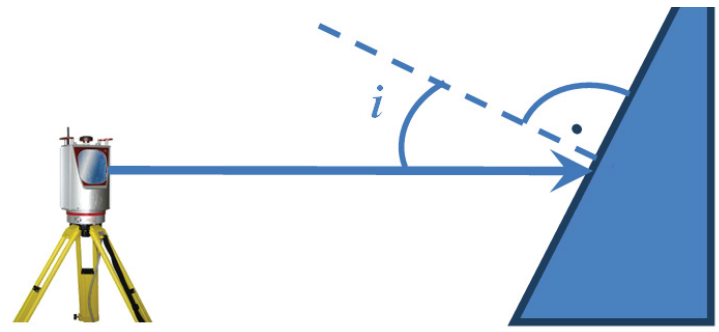

Fig. 2. Cosine correction of angle of incidence - i, incidence angle in relation to the normal on a point/pixel

In accordance with (Mleczko and Mróz, 2012) the angle required for the realization of (1) can be calculated from the formula (2).

$$
\cos i(x, y, z)=\cos \theta_{S} \cos \theta_{n}(x, y, z)+\sin \theta_{S} \sin \theta_{n} \cos \left\{\varphi_{S}-\varphi_{n}(x, y, z)\right\}
$$

where:

$\mathrm{I}_{\mathrm{H}}$ - intensity observed for vertical surface,

$\mathrm{I}_{\mathrm{S}}$ - intensity observed for sloped surface,

$\mathrm{i}$ - incidence angle in relation to the normal on a point/pixel,

$\theta_{\mathrm{s}}-$ instrument zenith angle,

$\theta_{\mathrm{n}}-$ surface slope,

$\varphi_{\mathrm{s}}-$ instrument azimuth,

$\varphi_{\mathrm{n}}-$ surface azimuth.

For the sake of simplification of calculations for individual points of the registered point cloud and considering that the angle of inclination of the concrete block cannot be described as one curve, the norm of the plane in each individual point was determined based on 4 neighbouring points, by assigning a plane to that particular set of points.

Due to high variability of insolation of the surfaces located in the areas accessible during the day an experiment was carried out aiming to identify the influence of an object's surface insolation on the results of terrestrial laser scanning. An inclined surface of a 44-metre high concrete construction was scanned twice: in the morning (air temperature $\mathrm{t}=10^{\circ} \mathrm{C}$ ) and in the evening $\left(\mathrm{t}=8^{\circ} \mathrm{C}\right)$. Because of its location, during good weather, the North-Western wall is subjected to high insolation and the daily difference in temperature recorded on the wall's surface is equal to $30^{\circ} \mathrm{C}$ in Autumn (at the turn of September and October). A Leica Nova MS50 scanning total station (Figure 3) was used. The temperature differences between the registered I (Intensity) values for the selected areas were compared. Table 1 juxtaposes the percentage changes in the I values in regard to the time of recording (10:00 AM), within 
a 10 hour long solar operation. The first column of table 1 presents the selected areas of the scanned concrete surface.

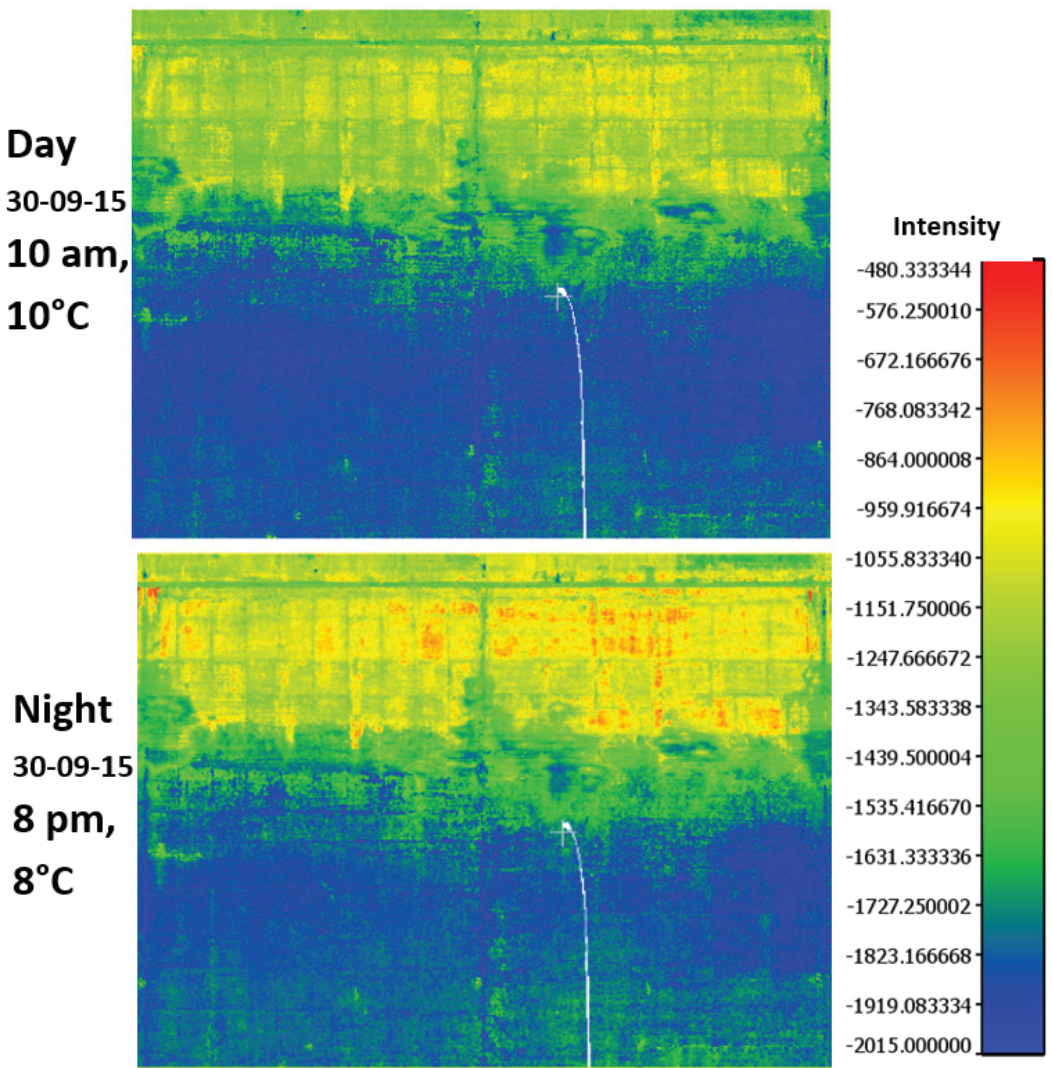

Fig. 3. The scanning results of the massive concrete construction at different times of day

Table 1. Changes in the registered values for the selected areas of a concrete surface at $10 \mathrm{AM}-8 \mathrm{PM}$ (10 hour interval)

\begin{tabular}{|c|c|c|c|c|c|c|}
\hline 1 & \multirow{2}{*}{ Area } & $\begin{array}{c}\text { Mean } \\
\text { Intensity } \\
\text { value }-10 \mathrm{am}\end{array}$ & $\begin{array}{c}\text { Mean } \\
\text { Intensity } \\
\text { value }-8 \mathrm{pm}\end{array}$ & $\begin{array}{c}\text { Difference } \\
(\Delta \mathrm{I})\end{array}$ & $\begin{array}{c}\% \\
(\text { about })\end{array}$ \\
\cline { 2 - 7 } & 1 & -2010 & -1870 & 140 & 10 \\
\hline & 2 & -1050 & -650 & 400 & 40 \\
\hline & & -1250 & -1050 & 200 & 25 \\
\hline
\end{tabular}


On the basis of the analysis of the registered intensity values of the reflected laser beam and the temperature changes it was concluded that:

- the influence of the air temperature, concrete type and insolation on the values of the measured $\mathrm{x}, \mathrm{y}, \mathrm{z}$ coordinates (differences below the scanning accuracy estimated at $0,005 \mathrm{~m}$ ) is negligible,

- significant influence of isolation changes and concrete temperature on the registered intensity of the laser beam, especially for brightly coloured areas (upper part of the scan) - these changes can be significant in assessing the technical condition of an object, which indicates the validity of data from other sources, eg. thermal camera.

The concept of integrating a thermal camera with a terrestrial laser scanner is comparable to a commonly known integration of a photographic camera with a scanner or a total station. The measurement sequence involves a scan, which creates a point cloud (xyz and I), then the thermal camera is used to take pictures that through the firmware are combined into a panorama. On the basis of common distinctive points which are identified manually or automatically, LaserControl V8.8.0 colours the point clouds using the data from thermal panorama as reference. During thermal image processing the material from which the surveyed surface is made is defined. The final product takes the form of a point cloud, where each point is defined not only by its coordinates but also Intensity and Temperature values (Figure 4).
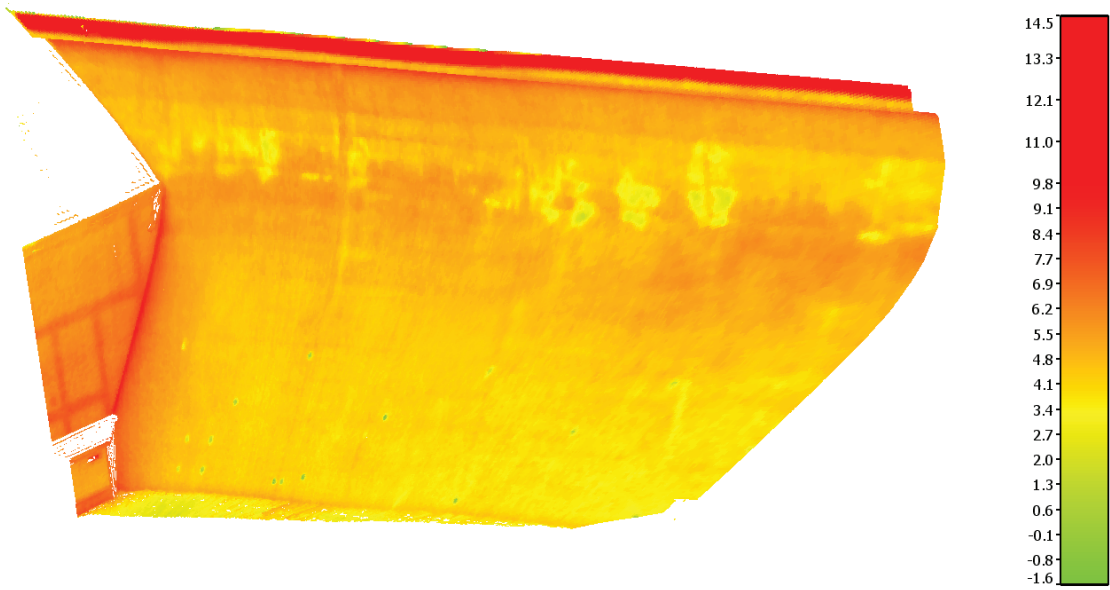

Fig. 4. Point Cloud coloured using the registered temperature (picture present fragment of the central part of the downstream wall of a water dam in Rożnów)

Accuracy of the obtained study depends on the scan's parameters, type and characteristics of the thermal camera and its calibration.

The acquired thermal images will be influenced by the object's surroundings. Thus, one has to take into consideration factors such as beam's incidence angle, 
surfaces inclination angle and external lighting. These types of corrections are introduced i.a. during satellite image processing (Osińska-Skotak, 2007). Acquisition of integrated thermal and geometric data (point clouds) may be an ideal opportunity to introduce these kinds of corrections. This issue will be the topic of further publications.

\section{Results and discussions}

The analysis of the registered intensity values can be used to analyse the surface of an engineering site. Concrete in large mass constructions is vulnerable to many factors which can lead to accelerated deterioration of an object. These factors include, among others: plastic contraction, tension due to differences in humidity and temperature in drying concrete and its surroundings, tension due to temperature changes, uneven settling of the ground beneath the structure, tectonic and seismic movements of the ground beneath the structure, rising water levels, changing ground parameters. Other factors that should be taken into account are such as: chemical aggression of precipitation, pressure caused by water freezing in concrete capillaries, changes in temperature, air humidity, fog, precipitation, grating and cavitation factors, microorganisms, plants, animals, excessive or changing workload are caused by utilization of the structure. Cumulative influence of the mentioned factors commonly causes the first signs of wear on the material or the construction itself in a span of roughly 5 to 15 years. These can show as scratches or scoring on the concrete mass, increased filtration or leaks in the construction, surface destruction of the concrete, excessive deformation and other symptoms (Kiljan, 2007). Most of the aforementioned factors can be diagnosed by geometric and spectral analysis of a registered point cloud.

To visualize these capabilities, an analysis has been performed on a downstream wall of a concrete water dam in Rożnów (Figures 5,6 and 7). A vertical fragment of the scan has been chosen due to the greatest shifts in the angle of inclination of the laser beam in that direction. The first step towards monitoring changes and deformation in the surface is an appropriate data preparation and thereby inclusion of adjustments. Values of the intensity observed for vertical surface $\left(\mathrm{I}_{\mathrm{H}}\right)$ for individual cloud points have been calculated. The obtained results are presented in Figure 6. Difference between initial $\mathrm{I}$ values and $\mathrm{I}_{\mathrm{H}}$ values are presented in Figure 7. 


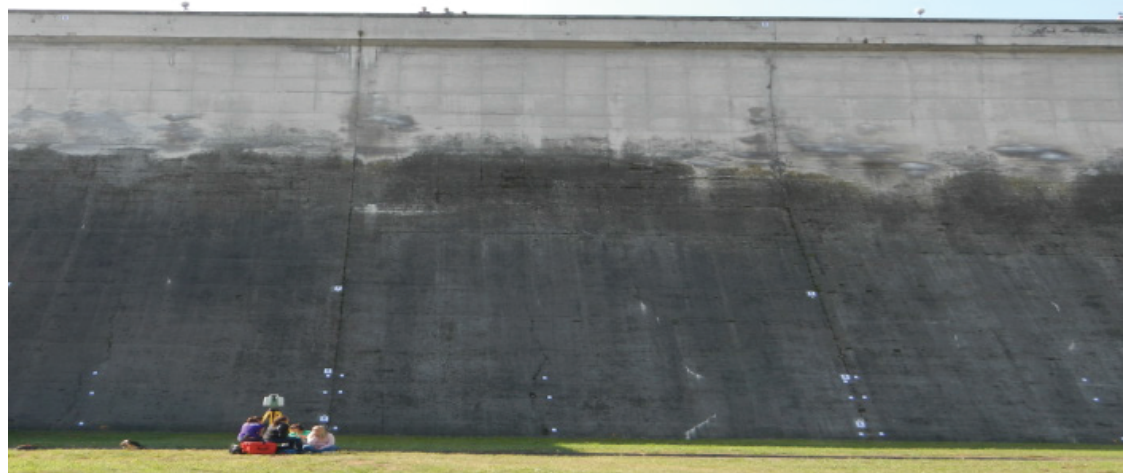

Fig. 5. Optical photo of the fragment of the tested concrete wall

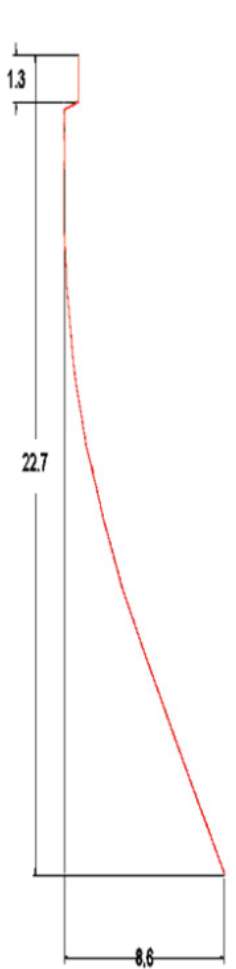

(a)

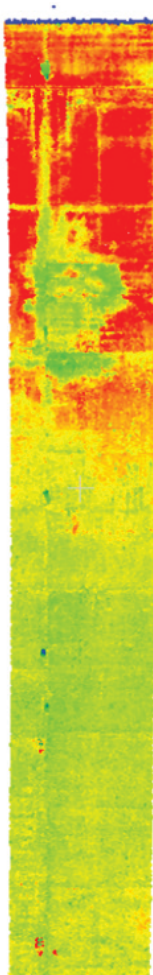

(b)

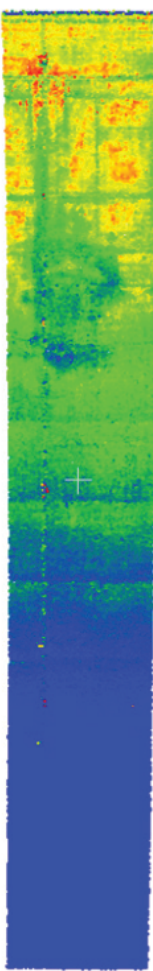

(c)

Fig. 6. A fragment of the scan in intensity colour scale: (a) cross section of the wall (b) original data, (c) data after $\mathrm{I}_{\mathrm{H}}$ adjustments 


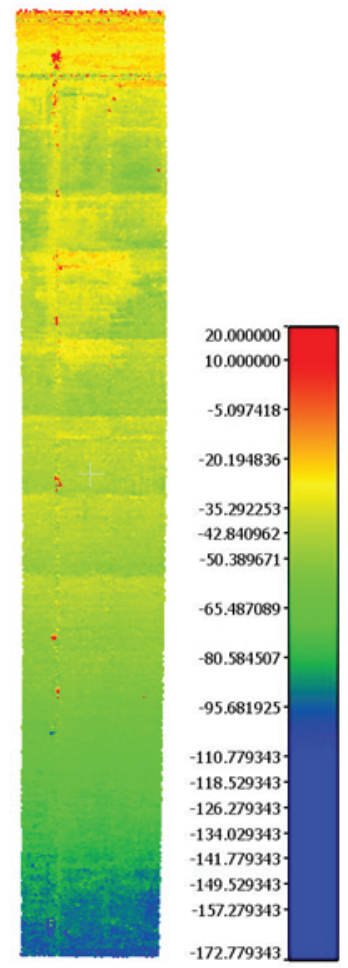

Fig. 7. Colour visualization of $\mathrm{I}-\mathrm{I}_{\mathrm{H}}$ differences on the surface of the dam wall

As can be observed, the highest values of adjustment fall on the lowest fragments of the tested area, the part of the wall with the largest inclination, while the lowest values relate only to the vertical direction of the laser beam fall on the vertical surface of the upper fragment of the wall. Local abnormalities in the magnitude of implemented adjustment are connected to the non-uniformity of the tested surface which is rough textured, polluted, covered in plant life and filtration sediment, and eroded. Data prepared this way can constitute a lead for further analyses, provided in the later part of this article.

Evaluation of the surface condition requires a multi-aspect analysis of data. We often make use of data from multiple sources, such as point clouds, thermal imaging, or data from the monitoring system of the evaluated construction A joint coverage of the multi-source data allows for a fuller evaluation of the object. Due to the character of the data, the analysis of the TLS point cloud can be conducted in two directions: geometric analysis based on the coordinates of the points and spectral analysis based on the registered I values. The geometric analysis provides information on surface deformations while intensity analysis provides its coverage.

Figure 8 collates the picture of intensity and thermal colour scale of the evaluated dam wall fragment, a distance map representing the distance of the points from the 
reference plane integrated into the point cloud and the photograph of the analysed experimental area. The collated data shows that while monitoring deformation in anthropogenic objects one should use information from different sources. By analysing the intensity image we acquire information on the imperfection and pollution of the tested surface (blue colour) and existing leaks (red colour). The thermal image shows differences of the temperatures in different places. The distance map provides information on any deformities (indentations, protuberances, scratches), while the photograph allows for visual confirmation of the results.
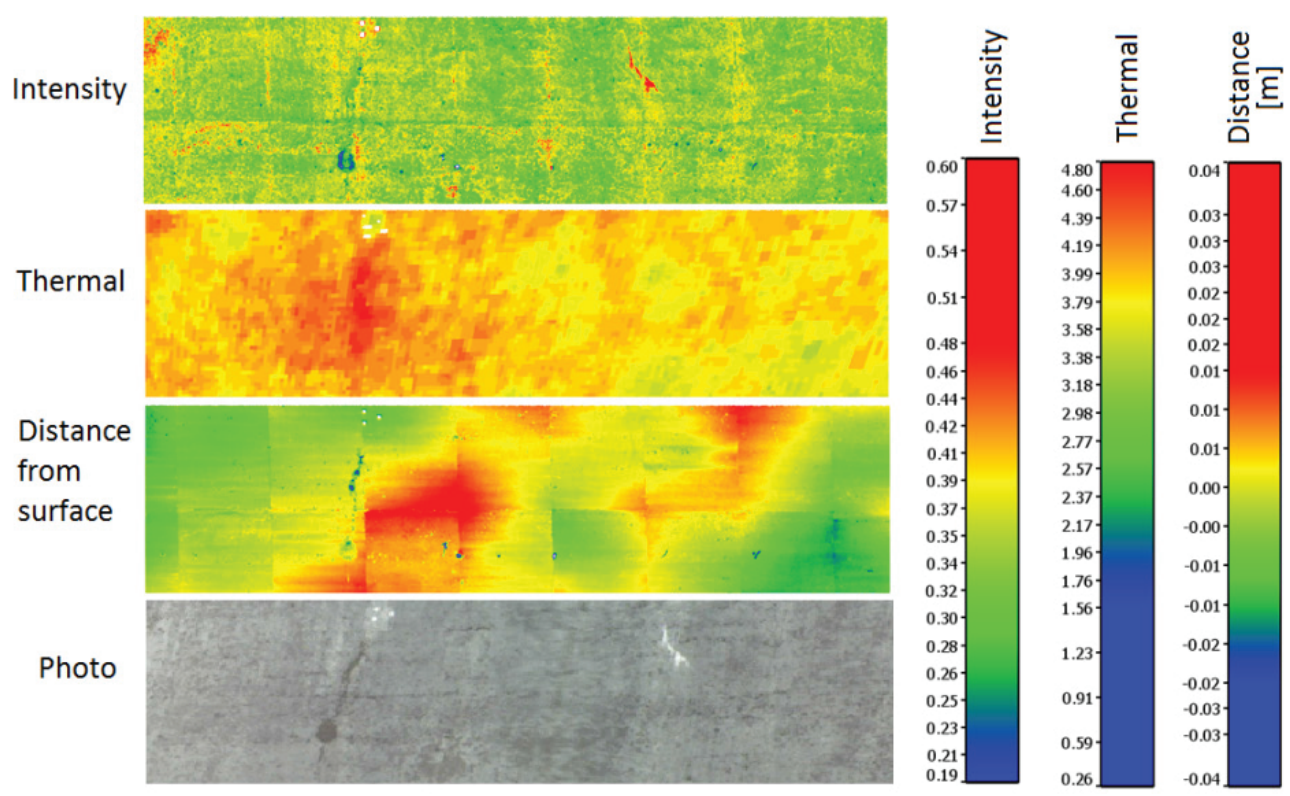

Fig. 8. Collation of the images of intensity, thermal values and the distance map of point distance from the integrated average plane shown in colour scale, and photograph of the analysed test area

Surface deformation analysis should be done for areas of appropriately chosen size. By analysing a smaller area and choosing an individual colour scale we arrive at better and therefore more detailed information on the tested area.

\section{Application of multi-source data in assessing the condition of concrete surfaces}

The experimental research presented in the further part of the paper was prepare using scan of the gravity concrete water dam that was carried out in Rożnów - scan of the central fragment of the concrete downstream wall of the water dam was carried out at the end of September 2015 and it was performed from two sites: 
1) Site 1 was located in the middle of the downstream wall in the distance of $50 \mathrm{~m}$ -3 measurements at a different time of day were performed. Each time a point cloud corresponding to the whole surveyed surface was obtained.

2) Site 2 was located in front of the left part of the downstream wall in the distance of $15 \mathrm{~m} .2$ measurements were performed at a different time of day.

All of the scans were transformed to a uniform coordinate system defined by the signalised merge points. Those points were measured using a total station and their coordinates were defined in the object's local system.

Figure 10 presents the results of a scan of the downstream wall's surface from site 1. Owing to the thermal data superimposed on the point cloud it is easy to notice how the surveyed surface heats up during the day. Uneven heating of the surface can be observed. In the upper part of scans (Figure 9) one can observe distinguishable irregular "spherical" areas. The said areas are characterised by properties different than those of concrete (calcium carbonate leakage). They are clearly visible in optical RGB image (Figure 5).

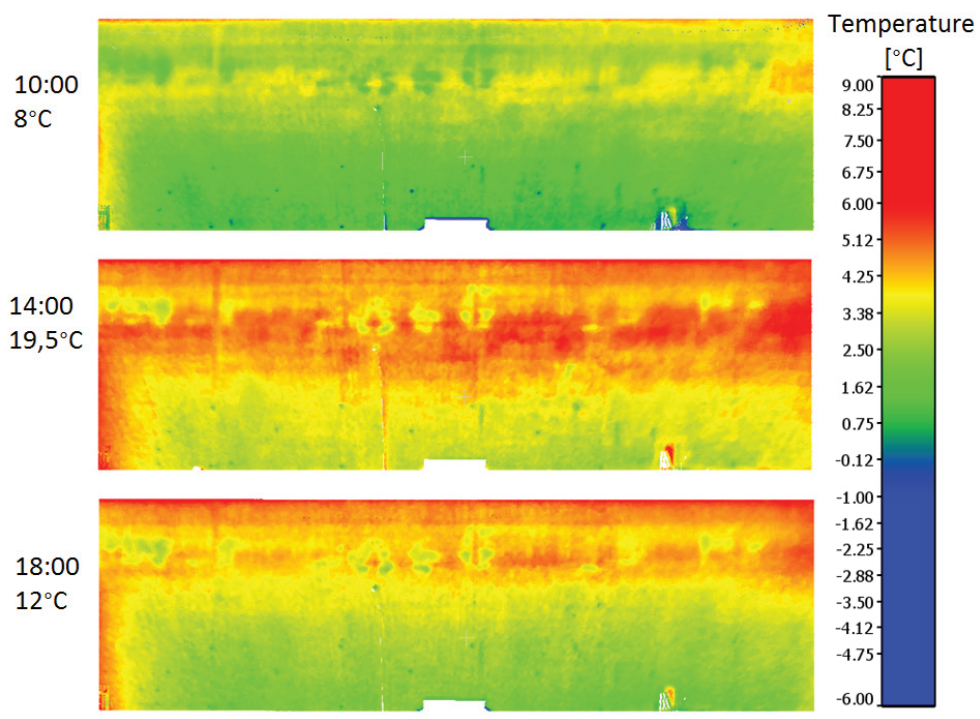

Fig. 9. Juxtaposition of scans coloured using thermal data acquired from the same site at different times of day (pictures taken subsequently, over one day, at 10:00, 14:00 and 18:00)

The presented example does not fully utilise the potential of the data acquired through terrestrial laser scanning. It is only based on analysis of thermal data with omission of point cloud geometry. In this case the geometric data could be used to calibrate the image, in order to eliminate the influence of the previously mentioned external factors on the acquired thermal data. After geometric calibration it is possible to perform analyses aimed at providing details on the genesis of the diversification of the registered temperature differences between selected areas (e.g. top and bottom of 
the construction). Identification of the level of influence of the surface inclination, thereby illumination angle will make it possible to analyse the condition of the surface on the basis of corrected data. This in turn will increase reliability of the acquired thermal data and condition assessment.

Through the integration of the data from terrestrial laser scanning with thermal data it is possible to directly, without any distortions, compare thermal and intensity images. Figure 10 clearly shows that thermal and intensity images contain information which can supplement one another. Using only intensity image it would be impossible to notice, that the area around point 1 possesses locally different surface thermal properties, which can indicate an existence of a crevice, crack or increased filtration. Using thermal data as basis it is also possible to note that the leakages present in the vicinity of point 2 heat up much slower than the rest of the surface, which diametrically changes the way the material works and in turn may result in increased surface erosion. One can observe how thermal dilatation between closed sections of the dam work. With appropriate selection of the analysed temperature and colour range one can highlight the analysed aspects. Thanks to a geometrically uniform data layout it is possible to compare registered data and analyse it in differential aspect.

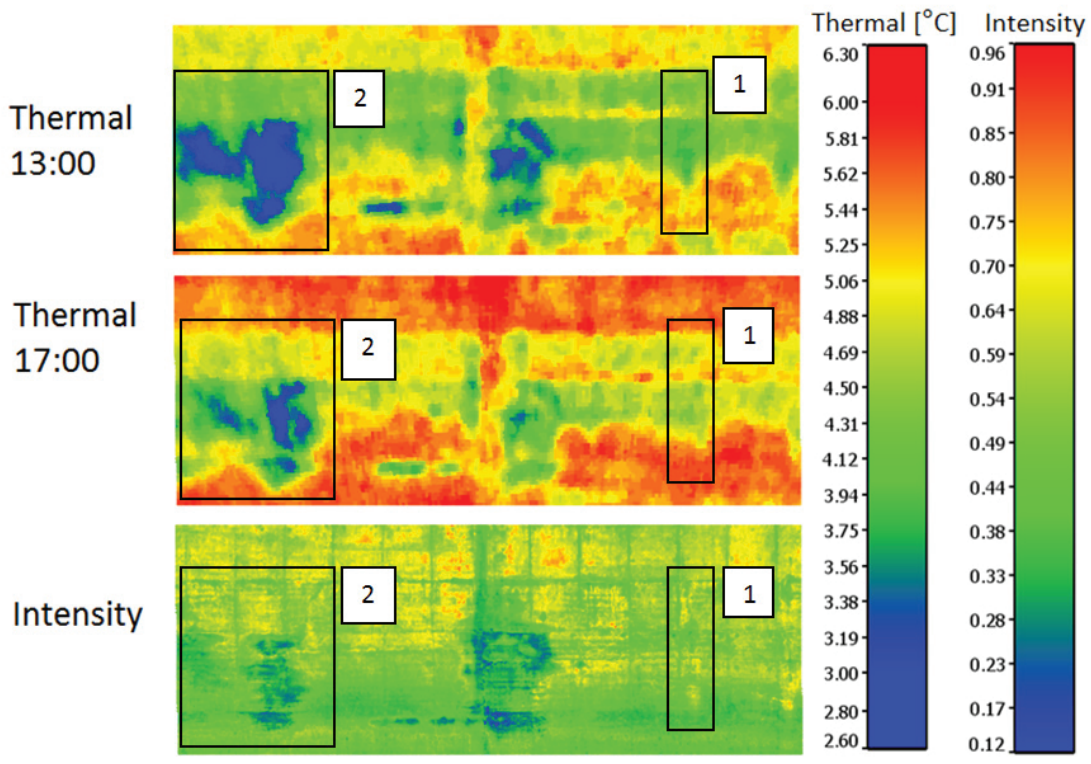

Fig. 10. Juxtaposition of a thermal images and intensity image for a selected fragment of a downstream wall belonging to a dam in Rożnów

Thermal data can also be used in order to study behaviour of crevices and cracks. Using data from the second measurement site a comparison of thermal data registered at 13:00 and 17:00 was made. Figure 11 presents the fragment of the clouds registered at two times of day coloured using temperature values and intensity values. For the 
purposes of thermal data analysis 3 xyz points were selected where the temperature was measured for both clouds.

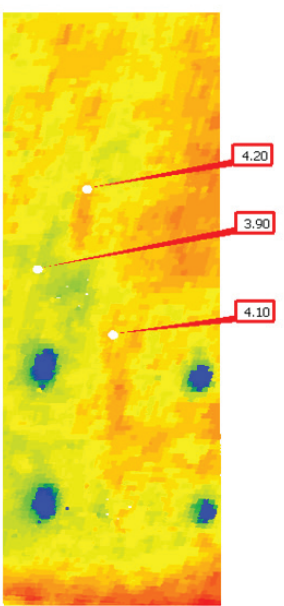

Thermal 13:00

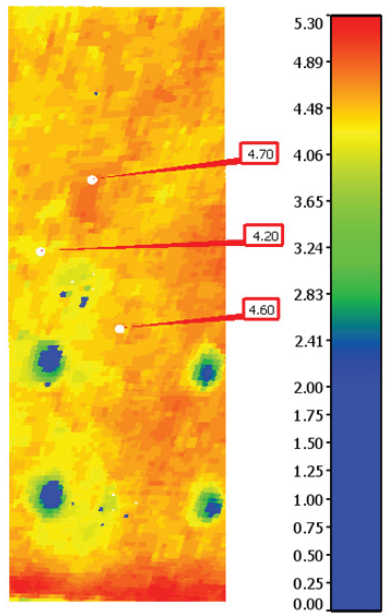

Thermal 17:00

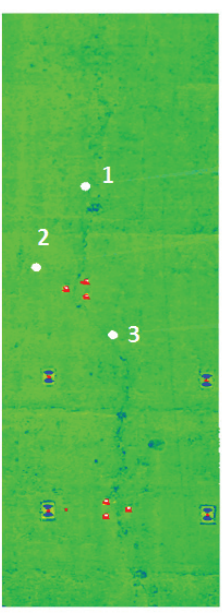

Intensity

Fig. 11. Registered thermal values at 13:00 and at 17:00 and Intensity values for a selected fragment of the downstream wall of the water dam in Rożnów

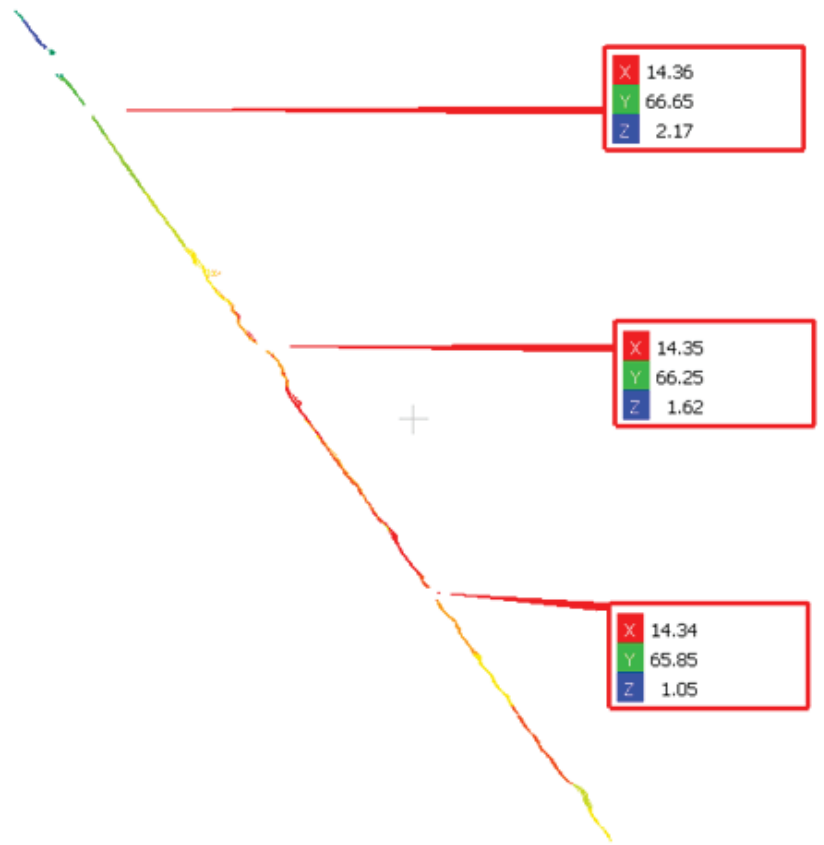

Fig. 12. Example of a cross section throw the selected crack 
Points 1 and 3 were placed in the area where cracks were located - in the immediate range of the analysed crack, whereas point 2 was selected as reference point located outside the cracked area. By analysing the calculated temperature differences a faster increase in temperature can be noticed in the crack than on the surface surrounding the crack (changes equal to $0.9^{\circ} \mathrm{C}$ and $0.5^{\circ} \mathrm{C}$ accordingly). The author would like to emphasize aspect of the resolution of the thermal image. For the selected fragment of the thermal image the pixel size equals to $5 \times 5 \mathrm{~cm}$. In the case of points selected on the edges of the crack the obtained temperature will be a mean value for an area of $25 \mathrm{~cm}^{2}$.

Point clouds acquired through terrestrial laser scanning may be used for, apart from thermal analysis, geometric analysis of the selected crack (Figure 12). One can determine geometric characteristics of the crack, like width or depth, in the selected sections by fitting appropriate planes into the selected fragment of the point cloud.

\section{Conclusions}

A laser beam carries information about a point's position in space. It is an electromagnetic wave that is subject to physical phenomena related to its reflection, diffusion and absorption, which in turn depend on properties of the surface the beam falls on. Thus Intensity values registered by a scanning device depend on the amount of radiation that is returned towards the radiation receiver. Radiation is strictly correlated with material structure and coating of the analysed surface. During an analysis of Intensity values recorded by a laser scanner the main challenge is to eliminate factors that distort the data on laser beam reflection: angle of incidence and distance. The method of Intensity value correction presented in this article compensates for the influence of angle of incidence on the surveyed surface and thus allows to perform a reliable analysis of spectral data.

Terrestrial laser scanning allows for creation of complex publications and analyses that have not been available to any of the surveying methods used in the fields of construction and hydrotechnics. Preparation of studies of almost any fragment of an object without the necessity to carry out additional field works is possible due to the method of data registration that results in the creation of a point cloud representing the geometry of the scanned objects. One of the significant advantages of this method lies in the speed at which huge amounts of data are being registered. Thanks to the integrated thermal camera, additional information is obtained through joint analysis of the registered intensity of the reflected laser beam from the surveyed surface and its temperature. Thermograms can be analysed for any projection and section based on once registered data for any part of a building if/when such needs arise. Moreover, the surveys can be easily repeated, compared and their results are easy to present.

One has to remember, that digitalisation of phenomena and objects carried out during the measurement that is point cloud registration, and subsequently visualisation 
of the data in the form of spectral images: intensity and temperature, imposes the method of preliminary data processing, calculation, result analysis and their visualisation. The obtained scans and thermograms differ in terms of resolution. The generated intensity and thermal images are acquired through data averaging for the selected window. However, the resolution of thermal data is limited to max. $5 \times 5 \mathrm{~cm}$. Selection of points and areas subject to surveying and evaluation should be performed after consultation with specialists or on the basis of geodesists' work experience. The results of surveys carried out using laser scanning technique have to be consulted with construction engineers. One cannot assume that the results are comprehensive and not burdened with various instrumental and environmental errors.

Analysis of integrated data allows for a quick identification of changes in the material's surface that are often not registered by visual methods. Differences in the registered temperature and intensity values, especially in reference to periodic surveys performed in different weather and environment conditions (e.g. changes in water damming level in the reservoir) may indicate uneven construction work, local weakening of the material, soiling or surface erosion. Geometric analysis of the obtained scans helps to determine wall deformations and movement of object's characteristic construction elements. Data integration allows for multidimensional evaluation of the object's technical condition.

In this example the implementation of presented correction and integration data from different sensors allowed to compare data sets, identify areas of different levels of density and contamination, areas eroded due to exploitation and material weakening. A multi-dimensional analysis of changes in the object was possible due to a comprehensive, multi-source approach.

Terrestrial laser scanning is increasingly being used for the control of anthropogenic objects whose failure can affect the safety of human life and property. The point cloud algorithms used in building architectural and building models are insufficient to control deformation of objects and changes in their surface condition. For the results of the control measurements to be reliable should be taken into account not only the geometry of the object, but also the physical properties of the building material and the environmental impact on the object (eg surface temperature changes depending on the time of day and the degree of insolation). At the Faculty of Geodesy and Cartography of the Warsaw University of Technology, research is underway to develop a full methodology for recording, preparing and analysing of point clouds for the assessment of the state of engineering objects.

\section{Acknowledgment}

The research has been conducted with the frame of statutory research at the Warsaw University of Technology, Faculty of Geodesy and Cartography. 


\section{References}

Alberti, G., Boscutti, F., Pirotti, F., Bertacco, C., De Simon, G., Sigura, M., Cazorzi, F. and Bonfanti, P. (2013). A LiDAR-based approach for a multi-purpose characterization of Alpine forests: an Italian case study. iForest-Biogeosciences and Forestry, 6(3), 156-168, DOI: 10.3832/ifor0876-006.

Bucksch, A., Lindenbergh, R. and Van Ree, J. (2007). Error budget of terrestrial laser scanning: Influence of the intensity remission of the scan quality. Siberia Proceedings 3D-NordOst, 1-8. Novosibirsk, Russia. 1-8.

Crutchley, S. (2009). Using LiDAR in archaeological contexts: the English heritage experience and lessons learned. Laser Scanning for the Environmental Sciences(Ed. G.L. Heritage, A.R.G. Large). WileyBlackwell, 180-200.

Hancock, C. M., Roberts, G. W., Bisby, L., Cullen, M. and Arbuckle, J. (2012). Detecting Fire Damaged Concrete Using Laser Scanning. Proceedings of FIG Working Week 2012, Roma, https://www.fig. net/resources/proceedings/fig_proceedings/fig2012/. (Accessed 1st August 2016)

Jaboyedoff, M., Oppikofer, T., Abbelan, A., Derron, M-H., Loye, A., Metzger, R. and Pedrazzini, A. (2012). Use of LiDAR in landslide investigations: a review. Natural Hazards, 61 (1): 5-28, DOI: 10.1007/s11069-010-9634-2.

Kaasalainen, S., Jaakkola, A., Kaasalainen, M., Krooks, A. and Kukko, A. (2011). Analysis of Incidence Angle and Distance Effects on Terrestrial Laser Scanner Intensity: Search for Correction Methods. Remote Sensing, 3(10), 2207-2221, doi:10.3390/rs3102207.

Kaspar, M., Pospisil, J., stroner, M., Křemen, T. and Tejkal, M. (2004). Laser Scanning in Civil Engineering and Land Surveying. Editorship Vega spol. s ro Hradec Králové. Czech Republic: Vega s.r.o. 110. ISBN 80-900860-3-9.

Kilian W. (2007). Współczesne metody diagnostyki masywnych konstrukcji betonowych. Infrastruktura i ekologia terenów wiejskich, 4(2)/2007: 77-85.

Lerma García, J. L., Van Genechten, B. and Santana Quintero, M. (2008). 3D Risk Mapping. Theory and Practice on Terrestrial Laser Scanning. Training Material Based on Practical Applications. Universidad Politecnica de Valencia, Spain. 2008.

Lichti, D.D. and Gordon, S.J. (2004). Error Propagation in Directly Georeferenced Terrestrial Laser Scanner Point Clouds for Cultural Heritage Recording. Proc. of FIG Working Week, Athens, Greece, May: 22-27.

Milan, D. (2009). Terrestrial laser scan-derived topographic and roughness data for hydraulic modelling of gravel-bed rivers. Chapter 9 in Laser Scanning for the Environmental Sciences (Eds. G. L. Heritage and A.R.G. Large).Wiley-Blackwell.pages: 133-146.

Mleczko, M., Mróz, M. and Sawicki, P. (2012). Podstawy teoretyczne i przegląd metod oraz algorytmów korekcji radiometryczno-topograficznej radarowych obrazów satelitarnych. Archiwum Fotogrametrii, Kartografii i Teledetekcji, 23: 303-314

Owerko, T., Kwartnik-Pruc, A., Kocierz, R., Kuras, P., Ortyl, Ł. and Długosz, M. (2013). Geomorphometric monitoring of active slopes and their impact on post-glacier lake in the Tatra mountains. 13th International Multidisciplinary Scientific GeoConference SGEM 2013 Conference Proceedings, June 16-22, 2013, 2.International Multidisciplinary Scientific GeoConference SGEM2013, 245252, doi:10.5593/SGEM2013/BB2.V2/S09.032.

Rutkowska, G., Klepak O., Podawca K. (2013). Problemy strat ciepła w istniejących budynkach jednorodzinnych w kontekście błędów wykonawczych. Annual Set The Environment Protection, 2013: 2625-2639.

Valzano, V., Bandiera, A. and Beraldin, J. A. (2005). Realistic Representations of Cultural Heritage Sites and Objects Through Laser Scanner Information. National Research Council of Canada, Ottawa. pages $1-12$.

Pesci, A. and Teza, G. (2008). Effects of surface irregularities on intensity data from laser scanning: an experimental approach. Annals of Geophysics, 51(5-6): 839-848. 
Pętlicki, M. and Kinnard, C. (2016). Calving of Fuerza Aérea Glacier (Greenwich Island, Antarctica) observed with terrestrial laser scanning and continuous video monitoring. Journal of Glaciology, 62(235), 835-846, DOI: 10.1017/jog.2016.72.

Osińska-Skotak, K. (2007). Znaczenie korekcji radiometrycznej w procesie przetwarzania zdjęć satelitarnych." Archiwum Fotogrametrii, Kartografii i Teledetekcji 17, 2007.

Pfeifer, N., Dorninger, P., Haring, A. and Fan, H. (2007). Investigating Terrestrial Laser Scanning Intensity Data: Quality and Functional Relations. Proceedings of VIII International Conference on Optical 3-D Measurement Techniques, Zürich, Switzerland. pages: 328-337;

Rees, W.G. (2013). Physical Principles of Remote Sensing. Third Edition. Cambridge: Scott Polar Research Institute University of Cambridge, Cambridge University Press. 441 pages.

Soudarissanane, S., Van Ree, J., Bucksch, A. and Lindenbergh, R. (2007). Error budget of terrestrial laser scanning: influence of the incidence angle on the scan quality. Proceedings 3D-NordOst, 2007. pages $1-8$.

Wróbel, A. (2010). Termografia w pomiarach inwentarskich obiektów budowlanych (rozprawa habilitacyjna). Monografie 209, AGH. Kraków

Voegtle, T. and Wakaluk, S. (2009). Effects on the measurements of the terrestrial laser scanner HDS 6000 (Leica) caused by different object materials. Proceedings of ISPRS Work 38 (2009): 68-74.

Zaczek-Peplinska, J., Osińska-Skotak, K., Wujanz, D., and Kowalska, M. (2015a). Potential of image processing methods based on intensity values captured by TLS for surface condition assessment. (Eds. S. Sahinkaya and E. Kalipci), Digital Proceedings of ICOCEE - CAPPADOCIA2015, 1364-1372.

Zaczek-Peplinska, J., Kowalska, M. and Nowak, E. (2015b). Selection of reference fields for statistical analysis of point clouds (TLS) in a process of technical condition assessment of concrete water dam. (Eds.S. Sahinkaya and E. Kalipci), Digital Proceedings of ICOCEE - CAPPADOCIA2015, $1373-1383$.

Zaczek-Peplinska, J., Kowalska, M., Nowak, E., Osińska-Skotak, K. (2015c). Metodyka wykonania oceny stanu powierzchni masywnej konstrukcji betonowej na podstawie klasyfikacji obszarów jednorodnych chmur punktów (TLS). in J. Winter \& A. Wita, J. Winter \& A. Wita (Red.), Eksploatacja budowli piętrzących - diagnostyka i zapobieganie zagrożeniom (ss. 373-384). Instytut Meteorologii i Gospodarki Wodnej. Państwowy Instytut Badawczy, 2015.

Zaczek-Peplinska, J., Osińska-Skotak, K., Wujanz, D. and Kołakowska, M. (2014). Analysis of the possibility for using the results of terrestrial laser scanning (TLS) measurements and classification algorithms of images for the engineering structure surface condition assessment. Proceedings of the first Vertical Geology Conference, University of Lausanne. pages: 227-232.

Zaczek-Peplinska, J. and Osińska-Skotak, K. (2012). Możliwości wykorzystania intensywności odbicia promienia laserowego do oceny stanu powierzchni betonowego obiektu hydrotechnicznego Chapter I.20 in Zapory - bezpieczeństwo i kierunki rozwoju, Instytut Meteorologii i Gospodarki Wodnej, Warszawa. pages: 204-217. 